\title{
Advances in rock mechanics and future trends
}

\author{
BB Dhar \\ Former Director, CIMFR; Director (Research), AIU, Director (R\&IC), Amity University \\ profbbdhar@gmail.com
}

\section{INTRODUCTION}

Rock mechanics is an engineering discipline which is as old as 1770s. Coulomb of Mohr-Coulomb failure criteria fame carried out tests on rocks and presented the results in a paper to the French Academy. After about 150 years, Griffith proposed his theory of brittle material failure in 1921. At about the same time, Josef Stini, who recognized the importance of structural discontinuities on the engineering behaviour of rock masses, started teaching rock mechanics under the name 'Technical Geology' at the Vienna Technical University. He had published 333 papers and books during the ' 30 s to 50 's, and founded a journal on the subject. Karl Terzaghi analyzed the rock slides in the Panama Canal, and presented them to the first international Conference on Soil Mechanics and Foundation Engineering in 1936. All these Scientists made significant contributions to the fundamental basis of rock mechanics. The dam, landslide and mine disasters which occurred during the ' 60 s led to the formal development of rock mechanics as an engineering discipline in its own right.

Since then, rock mechanics has seen a number of developments in both theoretical and practical aspects. A number of techniques have been developed for rock mass characterization, tools developed for modeling and design, and techniques developed for excavation and support. Following gives the status of these developments, and the future direction the science and engineering of rock mechanics may take.

\section{DEVElopMEnTS IN ROCK MASS CHARACTERIZATION}

In any project related to rock mechanics, the determination of rock mass characteristics is considered main initial project phase. Today, numerous constitutive models of different authors are included in computer programs and corresponding input parameters must be entered for them. When designing underground structures, Mohr-Coulomb constitutive model and the material model of softening behaviour are most commonly used. Its input parameters can be determined with the use of standard field and laboratory rock and soil tests. For soft rock masses, deformations are more precisely modelled using a material model with kinematics hardening [3]. While many authors have presented post failure characteristics of rock in various research papers, Hoek-Brown empirical failure criterion is still treated as a plastic flow criterion in which case the analyses are made by using the plastic theory [4]. The theory is mainly based on the experience with numerical analyses of different practical problems that suggest basic post failure parameters. Therefore, there is a need for new developments in monitoring of rock masses directed towards a more precise determination of rock mass characteristics and post peak parameters after rock mass relaxation. One of the suggested ways is to design a modern way of calculating geological strength index GSI on recently excavated surfaces in addition to back analysis of measured deformations in the excavation phases. Also, during the execution of excavation process itself, a suitable solution must be given for each type of the geological structure. Along with the solution, possible failure mechanisms due to mutual intersections of discontinuities within rock mass should also be determined.

\section{DEVELOPMENTS IN NUMERICAL MODELLING}

For complex problems related to rock mechanics, such as roof fall, numerical modelling remains largely a tool for conceptual understanding and general studies. However, for relatively simpler projects, such as tunnel design and slope stability analysis, numerical modelling has become a beneficial tool. Advances in the field of computational/numerical methods in rock mechanics since the inception of computer era in various engineering fields over the last three decades is notable.

To assess the global scenario of rock and the disturbance introduced by engineering, constitutive laws have framed. The constitutive laws represent system geometry, initial and boundary conditions, in situ and induced stresses, and material failure characteristics. The numerical modelling techniques also include scale time effects, uncoupled and coupled physical processes, complex construction sequence, interactions between all system components and interfaces in both 2D and 3D spaces.

The recent advances in numerical modelling can be briefly summarized as follows:

- Development from continuum-based model such as FEM and discrete models such as BEM and DEM to meshless models, enriched FEM, GBEM and FVM have enhanced the computational methods and capability. This development has also led to evolution of simulating fractures in rock Significant advances in the mapping and representation of the fracture systems in fractured rocks by stochastic DFN models is commendable. This advance is especially useful development for fractured hard rocks and has been developed and applied to a large variety of problems where fluid flow is the main concern.

- Development of successful commercial software packages which can be used by both the research community and 
practicing engineers, such as the UDEC/3DEC/PFC DEM code group, FracMan/ MAFIC DFN codes, FLAC-2D and -3D FDM code groups, etc. The popularity of these software packages is largely due to their user-friendliness and PC-oriented operating environment, which enables the practicing engineers, students and researchers to run the models quickly without going through the special training required and the inconvenience when large, main-frame computers are needed. This user-friendliness is one of the important factors for the wide propagation of numerical modelling in civil engineering fields today.

- Development of various Multiphysics software to involve complex phenomenon of different physical processes in a single model has increased our accuracy to understand the behavior of rock. Software such as PFC, designed to be general in nature, providing flexibility to simulate any mechanical system, represents model by an assembly of particles. Though considerable developments have been made so far, there are issues of special importance that needs to be handled in numerical modelling for rock mechanics

- Representation of rock mass properties and behavior as an equivalent continuum - The most important factor that affect the numerical modelling results is the rock mass properties of rock. The laboratory tests are carried over intact rock and then the properties are converted to rock mass properties using certain empirical formulae. The rock mass properties, thus found, are assumed in an equivalent continua. This is termed as upscaling and homogenization of the rock mass properties, which is necessary to obtain a numerical solution. The assumption of constitutive representations of rock matrix and joints in an equivalent continua remain an issue of particular difficulty.

- Numerical representation of engineering processes, such as excavation sequence, grouting and reinforcement Though numerical modelling follows a predictive tool, it is not satisfactory to consider only the initial and final states of a model. When dealing with complex geometries such as ore bodies in mines, it is important to follow and predict the complete stress path during different stages of excavations. Effects of grouting and reinforcements need to be studied in detail to assess the long term contributions in overall stability of excavations. Thus, the computer codes should be able to incorporate the effects of contact surfaces in addition to supporting elements and materials. A combined approach of empirical and numerical methods is required to achieve the same.

- Interface behavior - Interfaces are present in every rock projects in one form or the other. Interfaces shared between backfill and rock in case of mining, shear zones in case of geology, canister-bentonite, bentonite-rock and backfill-rock in case of radioactive waste repository are typical examples. Till date, there is no experimental basis for understanding the behavior of different interfaces and much less developments have been made in the same.

- Large-scale computational capacities - Large scale commercial codes such as ABAQUS, DIANA, etc are available, they all follow standard structural analysis codes and lack important capabilities for rock mechanics and engineering problems. There is a need for enhanced computational power to understand the behavior of rock in detail in the near future. Developments in parallel solution techniques may be one of the suggested approach.

- Scale and time effects - The time-dependent (creep) behavior of rock and the dynamic behavior of rock excavation, and scaling (scale dependency of physical properties and geometry) is the most common problems faced during numerical modelling. These factors are difficult to determine by either experimental or mathematical means. The dynamic values of all material properties are usually measured in static conditions because of lack of understanding and efficient mathematical models

- The above issues cannot cover all points of difficulty in numerical modelling in rock mechanics. Other issues of significance are the need for more laboratory and in situ experiments for verification of numerical methods, codes and models with well-controlled testing conditions and large enough sample sizes, and the need for more efforts in the combined applications of different modelling approaches, especially the $1: 1$ and not $1: 1$ modelling approaches, such as using rock mass classification with more numerically based methods.

\section{DeVElopments In PhysicAl ModELling}

In 1980's physical modelling was one of the main methods to identify the geotechnical problems. However, rapid developments in computational power and numerical methods, numerical modelling has become the preferred choice. Complexity and uncertainty of geological conditions and complex geotechnical issues have posed greater challenge to numerical modelling. Over a period of time, again significance of physical modelling has caught the attention of the researchers. Attempts are made to combine the advantages of both the models. Li et al. [2] created a 3-D geo-mechanical model of the underground caverns of the Xiluodu hydropower station, China, combining the advantages some of the primary principles of the numerical method with the physical model process. Considering that the boundary condition has a great effect on the stress distribution, a larger test model was set up. The numerical discrete principle was also used to simulate an initial geostress field.

As per the basic principle of cavern excavation that loading comes first, followed by excavation, a new technique, in which a high-fidelity simulation of the excavation process and a very difficult cavern excavation were successfully achieved. The new method produced test results more satisfactorily, and this simulation was an obvious improvement of existing techniques. The results of the tests were compared with FLAC-3D model results. The displacement distribution form and global trend were the same in the data from both techniques, with a slight difference in the displacement values. The horizontal displacement results from the two methods were quite similar, but the vertical displacement in the numerical model 
was a little less than that of the physical model, which may be due to the fact that the numerical analysis did not simulate the joints and beddings as much as the physical model, and can not completely simulate the boundary conditions of the model.

Comparison of the two methods showed that the effect of the physical model test was satisfactory, and that some geological weak structures are difficult to simulate numerically. Both numerical simulations and physical model tests have their own advantages, and combining the advantages of the two methods enabled to overcome many difficult problems. For some moderate and small-scaled projects, numerical simulation can generally solve problems sufficiently. But for large or huge scaled underground projects, physical model testing is also a competitive method. To further the development of physical model tests, it is important to introduce more new and advanced technologies to be used in 3-D model tests.

Zhang et al. [6] investigated the stability of an underground cavern group on the basis of large-scale 3D geomechanical model tests and numerical simulations. Multiple measurement techniques were developed to measure the convergence in the cavern, displacements at key points in the side walls and the damage pattern during the excavation process. The digital photogrammetric technique and fibre Bragg grating (FBG) based displacement sensing bars were applied to measure displacements in the surrounding rock mass. Mini multi-point extensometers with high-precision grating scales are developed as transducers for displacement monitoring. Results were compared with numerical modelling results of a nodal-based discontinuous deformation analysis method.

\section{New TRENDS In Rock Slope StabiLITY}

There has been new approaches introduced to assess the slope stability. The traditional method of calculating factor of safety of slop has provided insights for researchers to propose new approaches. One of them is partial factor method. According to this method, the stabilizing forces are greater than the driving forces in all scenarios except the one with the worst case. Another approach is probabilistic analysis. In this approach, the input parameters which vary within wide limits such as water pressure, seismic acceleration, friction angle etc. The analyses can be made based on the computer programs such as BestFit and @ Risk. Though new, these approaches must be tested while using the traditional deterministic approach and detailed comparison should be made. The approaches should be further investigated to determine the applicability of probabilistic methods to make a sound interpretation of calculated results.

\section{WIRELESS NETWORKING SYSTEM IN TUNNELLING}

One of the recent advances in rock mechanics is the introduction of wireless networking, especially in tunnelling projects. This has enabled to minimize the problems that occur during the construction phase due to lack of cooperation and communication between designers and contractors and lack of prompt expert decisions during onsite engineering.
From the civil engineering standpoint, stability of tunnels depends heavily on accurate prediction geological condition. Prompt actions are often required when engineers face natural problems such as changes of ground formation, presence of water in local area, geological discontinuities etc. Some problems occur due to carelessness of personnel, noncompliance with rules, underestimation of critical situations and communication gap between design and site teams. Thus, apart from skilled and experienced tea, continuous monitoring also plays an important role to keep health of the tunnel in check. The use of wireless networking enables continuous flow of information through the site, reducing the remedial cost and improving contract performance.

A wireless local area network (WLANs) provides a modern vision of management and information flow of construction sites. With use of IT (information technology) implemented in large industrial sectors, there is a need of it in construction sector as well. The WLAN system would provide more feedback of prevailing conditions than any other type of construction.

\section{LATEST Progress OF SOFt Rock MECHANICS AND ENGINEERING}

There has been a considerable progress of soft rock mechanics and engineering in China. With the increasing shortage of resources worldwide in shallow depth, the deep resources exploitation has been becoming a good alternative. In recent years, result, the disasters caused by large deformation of deep soft rocks have been increasingly developed, a serious threat to the safety of deep resources mining and the efficient development of underground space. In this regard, several studies have been conducted on modern mechanics and engineering geology with great progress in the concept and classification of soft rocks, in establishing a mechanism for transforming complex deformation, and in soft rock mechanics theory and technology systems, for which the core idea of energy security release was proposed. [1]. International Society for Rock Mechanics (ISRM) raised the definition of soft rock in 1981: "the International Society for Rock Mechanics (ISRM) describes rock with an UCS (uniaxial/compressive strength) in the range of $0.25 \mathrm{MPa}$ to 25 MPa as 'extremely weak' to 'weak', (ISRM, 1981). The basic mechanical properties of soft rock are critical load for softening and critical depth for softening. The studies have also allowed researchers to develop guidelines to develop classification of soft rocks. Several experiments have been made to assess the influence of water adsorption with time, clay mineral percentage using X-Ray Diffraction, pore texture, water vapour sorption in rock samples.

To comprehensively understand large deformation mechanism of soft rocks studies have been made to understand the characteristics of complex geomechanical environment, the unique physico-chemical composition of rocks, and the structure of rock mass. Researches have been made on swelling mechanism of clayey minerals in soft rocks, asymmetric large deformation mechanism of layered deep rock mass, large deformation mechanism of deep soft rock softening under high temperature, large deformation 
mechanism of soft rock rheology, and large deformation mechanism of soft rock rockburst.

According to the theoretical analysis and various engineering practices, the deformation mechanism of soft rocks can be classified into 3 categories. physical expansion type, stress dilatancy type and structure deformation type. Studies show that deformation mechanism of soft rock tunnels and roadway in mines is usually complex. Therefore, if we can successfully support the soft rock roadway, three key technologies are needed to be studied in detail: (1) adequate determination of composite deformation mechanism of soft rocks. (2) Effective transfer of complex deformation mechanism to a single type. (3) Effective use of the conversion technology of complex deformation mechanism.

The researchers in China have also developed a new material known as the constant resistance and large deformation (CRLD) bolt/anchor used for supporting excavations in soft rock. The interesting fact about the material is its negative Poisson's ratio i.e. the CRLD becomes thicker with increase in tensile force. The CRLD bolt/anchor can resist large deformation under constant resistance conditions, and it has the capacity to endure impact resistance and to absorb large deformation energy.

\section{RESEARCH NEEDS IN COAL MINING}

Peng [5] discussed research needs in 12 areas in coal mining where rock mechanics also plays major roles:

\section{A) Mine geology}

most ground control failures encountered in mining operations are geology-related. Bedding planes and laminations are the weakest parts of the sedimentary rocks. However, their role in controlling rock mass behaviours has been mostly ignored. There are so many bedding planes in the overburden, and, similarly, there are so many laminations within one layer of rock, especially shale. Most researchers select the bedding plane between weak (shale) and hard (sandstone) rocks as the control for bed separation and as the plane where lateral shifting of strata occurs and laminations are almost ignored. Most longwall or other methods of mining are designed based on the stratigraphic sequence constructed from few boreholes and the data between the boreholes are extrapolated. This results in design of uniform support system irrespective of the local changes in geology. Novel technique would be to map geology in and around the panel. If the drilling signatures in each borehole can be related to the strata drilled, then a detailed geological map can be constructed instantaneously, and roof supports changed accordingly. Once developed, all important geological changes from place to place can be addressed properly and in a timely manner.

\section{B) Rock Property}

The physico mechanical properties of many strata are not adequately represented as few samples from each strata are selected and the values are averaged out and there is no proper correlation between the intact rock properties determined in the laboratory and rock mass properties used in the design. Many weak rocks absorb moisture and deteriorate with time, some very rapidly. Those weak rocks are difficult to prepare for rock property determination in the laboratory because all recommended test methods of sample preparation prefer wet cutting and grinding; however, weak rocks cannot survive this vigorous preparation. Therefore, specimen preparation techniques for weak rocks that are sensitive to moisture need to be developed. All rocks exhibit timedependent behaviour, including failure, the amount of which depends on rock type and occurrence, especially sedimentary strata associated with coal mining. Some rock types such as clay-rich stone exhibit a considerable magnitude of timedependent behaviour. However, very few studies have considered this factor.

\section{C) Zones of Disturbances in Overburden}

The heights of caved and fractured zones have been used in ground control design like shield capacity determination and safety zone of aquifers in the overburden in the past few decades, but no definite measurement of those zones have been made. Many researchers have used the bulking factor concept to determine the height of caved zone and thus shield loading, but little, if any, research has been performed on the bulking factor of various rock types. Therefore, in practice, the assumed values of bulking factor have been used. The fractured zone height is very important. It determines the minimum safety distance between the coal seam top and the bottom of aquifer stratum or surface that must exist in order not to drain the aquifers or prevent the whole overburden from collapsing on the shield at the longwall face.

\section{D) Computer Modelling}

A software model is needed that can simulate the effects of mining and take into account all geology and mining operations simultaneously, including surface subsidence, overburden movement, panel layout, roof bolting, and bedding planes/ laminations. This is especially true for shallow longwalling where overburden disturbance continues from mining level to the surface. Current software is mostly restricted to one or more of these features, but not all of them simultaneously. When modelling without checking all the factors involved, the results could have only limited application. All rock mechanics theories are borrowed from continuum mechanics, but their application to ground control has been met with varying degrees of success. Need of the hour is to derive its own theories. We need constitutive equations involving nonlinear finite strains, time, and random and irregularly shaped rock blocks in a complete stress-strain curve. In the structural modelling of coal mines, most researchers assume that all rock strata are homogeneous, with some researchers taking the major bedding planes into consideration.

\section{E) Underground Stress Measurements}

In-situ stress measurements in US and other places suggest that there is considerable discrepancy in magnitude and orientation, even within different sections of a coal mine. More reliable methods of stress measurements are needed. Even measuring stress changes in coal pillars and abutment pressure in front of the longwall face needs to be installed in 
correct orientation and depths in order to capture correct behavoir.

\section{F) Research Methods}

Empirical approach tends to be a quick-fix solution and should not always be considered as the final solution. Understanding both the mechanisms of ground control events and how a specific ground control technique works is the only way to advance the science of ground control. Research is for developing new knowledge and theories. For ground control, research includes the application of new knowledge to the development of technologies, strategies, and products that address the needs of the industry.

\section{G) Roof Bolting}

In Majority of the cases, roof bolting pattern is fixed and surprisingly it works and design parameters are fixed and are restricted to bolt length and bolt type. The roof bolters are designed to install this pattern for maximum efficiency and are, thus, not amenable to any change in roof-bolting pattern. In recent years, computers have been employed for roofbolting design. Roof bolts are simulated by mathematical equations that might not be realistic because they do not consider the roof-bolt installation procedure. The hardware components of roof bolts by different manufacturers vary in such a way that computer modeling cannot truly simulate the details. Therefore, current computer models cannot tell the difference in performance between different manufacturers, which means that these models cannot accurately measure the effectiveness of different types of roof bolt.

\section{H) Coal Pillars}

There are numerous methods of pillar designs that can be found in the literature. Studies so far have identified many factors affecting coal pillar strength, including non-uniform stress distribution, lateral confinement, and the effects of roof/ floor strata, inhomogeneity, planes of weakness (i.e., cleat/beddings and fractures), and time. Therefore, a sound coal pillar design method should consider all of these factors.

All empirical pillar strength formulas in their derivation assume that the pillar is an isolated, single, standing support subjected to the weight of the overburden above it. Although worldwide in-situ stress measurements have proven that the vertical stress is equivalent to the weight of the overburden thickness, there are many cases illustrating that the pillar would fail if gravity loading is used as the pillar loading. Since overburden strata act like multiple overlapped beams, the gravity-loading concept seems the most conservative approach (i.e., overestimate the pillar loading). Since a beam subsides differently at different parts of the opening, the load on pillars under it will also vary. There is no consensus on the definition of pillar failure.

Different people and mines perceive pillar failure differently, due to different practices and safety concepts, and, as a result, everyone may define pillar failure differently. Therefore, when research is based on visits to coal mines and interviews with different people at different mines, the research is not uniform, and the conclusions drawn from the data may be biased.

\section{I) Failures}

Failure initiation in rock strata around mine structures does not necessarily lead to final collapse. In fact, in most cases, failures or fractures in practice either stabilize after the initial failure or propagate over time before the final collapse. Frequently, the failure or fracture stops after propagation for some length of time or distance. Whenever a large roof fall occurs, consultants are called. The consultants investigate the causes of the roof fall and make recommendations for changes in roof supports or mining operations. The investigation often neglects the fact that the roof fall occurred in that specific location but not in neighbouring locations. In that case, specific geological anomalies could be the cause of the roof fall, and no change in the existing roof support system is actually needed.

\section{J) Subsidence:}

There are two important issues in subsidence, surface structural damage and dewatering of water bodies. Considerable studies have been done and great advances have been made on surface subsidence prediction and the mitigation of surface structures. The opposite is true for dewatering. Therefore, the single most important subject on surface subsidence effects of underground mining is how underground mining affects water bodies in the overburden. For a groundwater dewatering study, models of water flow in porous media must be developed or used if available before mining. After mining, water-conducting fractures in the overburden within the water-conducting fracture zone must be considered. In some coalfields of the world, the overburden contains thick sands with abundant groundwater. In shallow depth, the saturated sand layers will break through the thin bedrock and flood the mine workings, very much like liquefied soils. This requires a threephase flow model (i.e., water and sand in fractured rock layers) that we don't have now.

\section{K) Shield Support}

Shield support is designed by determining the roof load to be encountered by the shield during longwall mining. The required roof load or shield capacity is expressed in the form of a formula or formulas. Some formulas are simple, while others are complicated with many difficult parameters. Shield design consists of four components: determination of roof loading, sufficient strength of structural components, and determination of floor rock strength in the presence of water if it exists, and fatigue strength of the shield, as a unit and as the structural components that make up the unit. Shield capacity is designated by its yield load, but the shield is put to work at a pre-set setting load that ranges from $40 \%$ to $90 \%$ of the yield load. Everything being equal, will two shields of the same yield load capacity — one with a $40 \%$ setting load and the other with a $90 \%$ setting load, work the same in terms of shield structure and roof behavior? Most researchers seem to agree that high setting to yield load ratio is preferred. If so, what would be the best setting to yield ratio? How does a low setting load differ from a higher one in terms of roof behaviour? To determine this, a shield should be designated by both yield load and the setting to yield load ratio. Methods 
available to predict shield yield load does not predicts increasing shield load requirements, however countries like China ever increasing shield capacities are used without any apparent benefits.

\section{L) Coal Bumps}

Although micro-seismic techniques were initially used in identifying the areas of high stress concentration and relieving the stress with drilling and blasting, the method it was not economical as the target area was large and quick moving. After more than half a century of continuing research, many theories have been developed about coal bumps and techniques, have been applied in an attempt to control them. However, coal bumps continue to occur without prior knowledge, causing severe injuries or fatalities. Much more research is needed to translate these findings into workable practice.

\section{FUTURE DIRECTIONS FOR ROCK ENGINEERING}

The demand for rock mechanics activities is evolving globally. The evolution is based on geopolitics, global economy and finance, energy and manufacturing demand and the environmental restrictions. The increasing use of renewable energy resources such as wind, solar, hydro, and geothermal as well as non-renewable resources such as nuclear, oil, natural gas and shale to produce energy has increased the demand for minerals, forcing the mines to go deeper, which in turn needs new continuous progress in rock mechanics. The construction of new infrastructures as well as rehabilitation of existing structure both surface and underground will also increase the demand for research in rock mechanics.

A relatively smaller budget have been allocated in Europe and North America while higher budgets have been allocated in Asia and South America. Large scale testing facilities are required for long term studies. For this, the government of each country along the international cooperation plays an important role. The privately funded research has increased lately since these companies have increased their financial capability and have a continuous urge to have an competitive edge. Many researchers concentrate more on developing new models but fail to produce comparative (with respect to real mechanisms) results for validation and quality control. Thus, there is a great importance of back-analysis, long-scale monitoring, full-scale testing facilities and open data dissemination. Cross-testing and verification should be encouraged for open, universal formats for testing as well as numerical modelling results. If the drilling signatures in each borehole can be related to the strata drilled, then a detailed geological map can be constructed instantaneously, and roof supports changed accordingly. Once developed, all important geological changes from place to place can be addressed properly and in a timely manner.

A detailed study is needed in future to compare the laboratory rock testing with micromechanical modelling. The loading mechanism from very fast loading to very slow loading to study the time effects is required to know whether a general phenomenological theory can be proposed.
The study of long time behaviour will enable us to define the life span of existing structures, linings and rock bolts. This may also provide insights in the evolution of stress fields around a large span tunnel in 100 years. An interdisciplinary topic, is fundamental for specific problems, but can also be the key to explain many aspects of rock mass behaviour.

New ways to deal with uncertainty by conducting massive simulations of various scenarios using parallel computing along with integration of more sophisticated risk analysis in everyday practice. The greater integration i.e. integrating engineering with geophysics, engineering geology, microcosmic, can drive research to greater levels in rock mechanics. Also, with more sophisticated field instruments such as the one that measure acoustic emissions, electric and magnetic fields, acceleration in parallel with force and displacement.

Imaging techniques have also been introduced in boreholes, rock faces, etc. using digital image processing and pattern recognition. Imaging plays an important role in rock mechanics to understand the geological parameters of the rock,

New methods need to be sought to understand highly stressed environments, predict and prevent rockbursts and predict earthquake triggering mechanisms. Space exploration may provide new information in rock mechanics because of different gravity and different mineral composition of the rock.

\section{REFERENCES}

[1] M. He, Latest progress of soft rock mechanics and engineering in China, Journal of Rock Mechanics and Geotechnical Engineering, 6, 165-179, 2014.

[2] Z.K. Li, H. Liu, R. Dai and X. Su. Application of numerical analysis principles and key technology for high fidelity simulation to 3-D physical model tests for underground caverns." Tunnelling and Underground Space Technology, 20(4), 390-399, 2005.

[3] D. Ocepek, New Trends in Rock Mass Characterization for Designing Geotechnical Structures, Acta Geotechnica Slovenica, L. Trauner, Univ. of Maribor, ISSN: 1854-0171, 2005.

[4] X.D. Pan, J.A. Hudson, A simplified three dimensional Hoek- Brown yield criterion. In: Romana M (ed) Rock mechanics and power plants. Balkema, Rotterdam, pp 95-103, 1988.

[5] S.S. Peng, Topical areas of research needs in ground control - a state of the art review on coal mine ground control, International Journal of Mining Science and Technology, vol. 25, no. 1, pp. 1-6, 2015.

[6] Q.B. Zhang, L. He and W.S. Zhu. "Displacement measurement techniques and numerical verification in 3D geomechanical model tests of an underground cavern group", Tunnelling and underground space technology, 56, 54-64, 2016. 